\title{
Neutronic evaluation of coating and cladding materials for accident tolerant fuels
}

\author{
Ian Younker ${ }^{\mathrm{a}}$, Massimiliano Fratoni ${ }^{\mathrm{b}, *}$ \\ ${ }^{a}$ The Pennsylvania State University, University Park PA, USA 16802 \\ ${ }^{b}$ University of California, Berkeley, Berkeley CA, USA 94720-1730
}

\begin{abstract}
In severe accident conditions with loss of active cooling in the core, zirconium alloys, used as fuel cladding materials for current light water reactors (LWR), undergo a rapid oxidation by high temperature steam with consequent hydrogen generation. Novel fuel technologies, named accident tolerant fuels (ATF), seek to improve the endurance of severe accident conditions in LWRs by eliminating or at least mitigating such detrimental steam-cladding interaction. Most ATF concepts are expected to work within the design framework of current and future light water reactors, and for that reason they must match or exceed the performance of conventional fuel in normal conditions. This study analyzed the neutronic performance of ATF when employed in both pressurized and boiling water reactors. Two concepts were evaluated: (1) coating the exterior of zirconium-alloy cladding with thin ceramics to limit the zirconium available for reaction with high-temperature steam; (2) replacing zirconium alloys with alternative materials possessing slower oxidation kinetics and reduced hydrogen production. Findings show that ceramic coatings should remain 10-30 $\mu \mathrm{m}$ thick to limit the neutronic penalty. Alternative cladding materials, with the exception of $\mathrm{SiC}$, enhance neutron loss compared to zirconium-alloys. An extensive parametric analysis concluded that reference performance metrics can be met by employing $300-\mu \mathrm{m}$ or less thick cladding or increasing fuel enrichment by up to $1.74 \%$ depending on material and geometry.
\end{abstract}

Keywords: accident tolerant fuel, light water reactors, ceramic coatings, cladding

\section{Introduction}

Many years of research and development on light water reactors (LWRs) cladding materials have produced zirconium alloys with slower oxidation kinetics, reduced hydrogen pick-up, and limited irradiation growth and creep [1], but these advancements under normal operating conditions do not translate to beyond designbasis accident (BDBA) conditions. During severe accident conditions with loss of active cooling in the core, similar to those experienced at the Fukushima Daiichi Nuclear Power Plant, concerns surrounding zirconiumalloy cladding arise: embrittlement from hydrogen pick-up leading to possible fracture and fission product release; hydrogen generation from the exothermic reaction with steam; lack of coolable geometry due to

*E-mail: maxfratoni@berkeley.edu

(C) 2015. This manuscript version is made available under the Elsevier user license http://www.elsevier.com/open-access/userlicense/1.0/ 
cladding deformation [2]. A large international effort is ongoing to engineer solutions that can enhance the capability of LWR fuel to withstand BDBA conditions by mitigating if not eliminating the detrimental interaction between zirconium alloys and steam, and as a minimum increasing the coping time for the reactor operators. These new solutions, designed for current and future LWRs, are referred to as accident tolerant fuels (ATF) [3]. When compared to conventional $\mathrm{UO}_{2} /$ zirconium-alloy fuel, ATF concepts are expected to provide enhanced performance, reliability, and safety characteristics during off-normal conditions while maintaining or improving performance during normal conditions. Among the many ATF concepts those that can be deployed in existing LWRs are of particular interest: (1) using a thin protective ceramic coating on the zirconium-alloy cladding exterior; (2) replacing zirconium alloys with alternative cladding materials.

Thin ceramic coatings look to provide a protective layer for the zirconium alloy that will reduce oxidation and hydrogen pick-up during normal operating conditions while significantly retarding oxidation kinetics and hydrogen production during BDBA conditions. Under normal operating conditions the requirements for coatings are to: adhere to the zirconium alloy, self-heal if defected, remain stable with respect to spalling and grid-to-rod fretting, and provide stable properties under irradiation. MAX phases are ideal coating candidates since they possess both ceramic (corrosion resistance) and metallic (high thermal conductivity) properties. MAX phases have the general formula $\mathrm{M}_{\mathrm{n}+1} \mathrm{AX}_{\mathrm{n}}$ where $\mathrm{n}=1,2$, or $3 ; \mathrm{M}$ is an early transition metal; $\mathrm{A}$ is an A-group element; and $\mathrm{X}$ is carbon or nitrogen [4]. About 60 different MAX phase compositions exist with various desirable properties such as resistance to chemical attack, low thermal expansion coefficients, and creep resistance. The Industry Advisory Committee to the Idaho National Laboratory Advanced Light Water Reactor Fuel Development Program has proposed applying a 10-20 $\mu \mathrm{m}$ thick MAX phase (e.g. $\mathrm{Ti}_{3} \mathrm{AlC}_{2}$ ) layer to zirconium alloys using thermal and cold spray techniques [5]. In addition to MAX phase, researchers at The Pennsylvania State University have proposed to use TiAlN as coating material [6]. TiAlN is a nano-composite material of TiN and AlN that improves oxidation resistance, corrosion resistance, and hardness, but exhibits limited thermal conductivity [7]. In a recent study [8], $1 \mu \mathrm{m}$ thick $\mathrm{Ti}_{0.35} \mathrm{Al}_{0.65} \mathrm{~N}$ coatings were deposited onto Zircaloy-4 tubing and exposed to deaerated $500{ }^{\circ} \mathrm{C}$ and $25 \mathrm{MPa}$ water for 48 hours. After exposure, the coated tubes showed reduced oxidation compared to the uncoated tubes because of a robust oxide layer formed on the coating surface.

Cladding materials alternative to zirconium-alloys that exhibit lower oxidation kinetics in high temperature steam environment include ceramics, stainless steels, and advanced metallic alloys. $\mathrm{SiC}$ is a ceramic that provides a higher melting temperature, reduced oxidation and heat of oxidation, reduced hydrogen generation under off-normal conditions, low chemical activity, and a lower neutron absorption cross section $[9,10]$. SiC cladding is a relatively new concept; manufacturing technologies are still under development, a proven solution to hermetically seal the fuel rod end plugs is yet to be found [11], neutron irradiation induces a reduction in thermal conductivity [12], and recent hydrothermal corrosion experiments showed significant mass loss of $\mathrm{SiC}$ in BWR-like conditions [13]. Ferritic stainless steel alloys, such as FeCrAl, have the ability to enhance oxidation resistance by creating a protective oxide layer; for instance, the aluminum found in 
$\mathrm{FeCrAl}$ combines with oxygen to produce an oxide layer $\left(\mathrm{Al}_{2} \mathrm{O}_{3}\right)$ capable of reducing oxidation kinetics in high temperature steam environments [1]. Austenitic stainless steels, such as Alloy 33 [14], offer resistance to highly oxidizing media, high yield strength and excellent toughness. TZM is an advanced molybdenum alloy features high thermal conductivity, low coefficient of expansion, and good ductility at low temperatures [15]. Molybdenum has very poor corrosion resistance when exposed to high purity, high temperature steam; therefore, reactor applications will likely require a thin tube molybdenum alloy coated with either zirconium alloy or advanced steels [16].

ATF concepts are expected to work within the framework of current and future LWRs; therefore, their viability besides improvements in BDBA conditions will strongly depend on the performance during normal operation. Among the advantages of zirconium-alloys is the very low neutron absorption. Most ATF concepts suggest replacing zirconium, partially or completely, with materials of higher neutron absorption and will negatively impact fuel cycle length and/or initial fuel enrichment. The purpose of this study is to assess the neutronic performance and evaluate design solutions to enhance such performance of previously described ATF concepts for use in both pressurized water reactors (PWRs) and boiling water reactors (BWRs). Section 2 describes the models used in the analysis. Section 3 illustrates the results obtained in terms of reactivity penalty, cycle length, and changes in fuel geometry and enrichment. Section 4 discusses the significance of these results.

\section{Models and Methodology}

The performance of ATFs was evaluated in PWRs and BWRs against that of conventional fuel. Neutronic calculations were performed using the Monte Carlo code Serpent [17]. The models used for the comparison are based on a single assembly and are described in this Section.

The PWR reference assembly is based on the AP1000 $17 \times 17$ fuel element [18]. It contains 264 fuel rods, 24 guide thimbles, and 1 instrumentation thimble (Figure 1). The corresponding core parameters are shown in Table 1. Reflective boundary conditions on four sides generate an infinite radial lattice of finite length. Assembly extremities consist of axial reflectors made of a mix of steel and water representative of those regions (50\%-50\% volume mix, $100 \mathrm{~cm}$ length). ENDF/B-VII cross sections were applied at the following temperatures: 1,057 K for fuel, $637 \mathrm{~K}$ for clad, $600 \mathrm{~K}$ for coolant, and thermal scattering cross sections were applied to water. Reference $\mathrm{UO}_{2}$ fuel was assumed enriched to 4.5 at.\% and Zircaloy-4 $(0.1 \%$ Cr, 0.21\% Fe, $1.45 \% \mathrm{Sn}$, and $98.24 \% \mathrm{Zr} ; 6.56 \mathrm{~g} / \mathrm{cm}^{3}$ ) was chosen as clad material. 
Table 1: Properties of the PWR reference design.

\begin{tabular}{lc}
\hline Property & Value \\
\hline Total Power, MW & 3,400 \\
Assemblies & 157 \\
Core average coolant temperature, ${ }^{\circ} \mathrm{C}$ & 303 \\
Pressure, bar & 155 \\
Core average coolant density, ${ }^{\circ} \mathrm{C}$ & 0.719 \\
Active length, cm & 427 \\
Pellet diameter, cm & 0.82 \\
Clad thickness, cm & 0.057 \\
Fuel rod outer diameter, cm & 0.95 \\
Pitch-to-diameter ratio & 1.326 \\
\hline
\end{tabular}

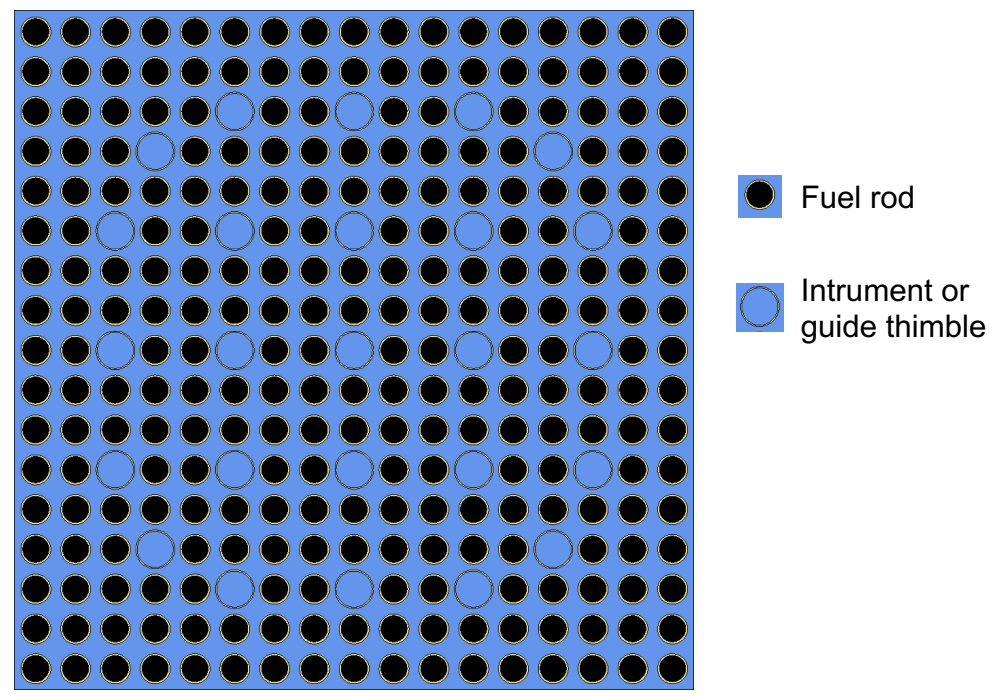

Figure 1: Reference AP1000 assembly as reproduced in Serpent.

The BWR reference assembly model is based on the GE14 10×10 design. Key parameters are summarized in Table 2 [19, 20, 21]. Such assembly contains 78 full length fuel rods, 14 partial length fuel rods (PLFR), and 2 water rods [19]. Four different axial regions were used to model uranium enrichment and gadolinium distributions [22]: (1) lower blanket, $15.24 \mathrm{~cm}$ long, composed of natural uranium; (2) lower dominant zone, $228.6 \mathrm{~cm}$; (3) upper vanishing zone, $106.68 \mathrm{~cm}$ and PLFRs vanish; (4) upper blanket, $17.53 \mathrm{~cm}$, composed of natural uranium blanket. Fuel rod cladding, water rod cladding, and channel box are made of Zircaloy-2 $(0.12 \% \mathrm{O}, 0.1 \% \mathrm{Cr}, 0.1 \% \mathrm{Fe}, 0.05 \% \mathrm{Ni}, 1.4 \% \mathrm{Sn}, 98.23 \% \mathrm{Zr})$. Water rod and channel box coolant are at inlet conditions, and remaining coolant was separated evenly into 24 axial zones of variable density [23]. Figure 2 shows radial and axial profiles of the reference BWR assembly. Reflective boundary conditions on four sides 
create an infinite radial lattice of finite length. Assembly axial extremities contain a bottom reflector made of a water and steel representative mix (50\%-50\% volume mix, $100 \mathrm{~cm}$ length), and a top reflector constructed of a water/steam mixture (84\% water and $16 \%$ steam), steam, and steel (35\%-35\%-30\% volume mix, $100 \mathrm{~cm}$ length). ENDF/B-VII cross sections were applied at the following temperatures: $928 \mathrm{~K}$ for fuel, $629 \mathrm{~K}$ for clad, $600 \mathrm{~K}$ for coolant, and thermal scattering cross sections were applied to the water.

Table 2: Properties of the BWR reference design.

\begin{tabular}{ll}
\hline Property & Value \\
\hline Pellet diameter, cm & 1.026 \\
Clad thickness, cm & 0.076 \\
Gap thickness, cm & 0.007 \\
Pitch-to-diameter ratio & 1.262 \\
Bundle unit total width, cm & 15.24 \\
Inter-bundle gap width, cm & 1.219 \\
Water rod diameter, cm & 2.590 \\
Water rod cladding thickness, cm & 0.076 \\
Shroud thickness, cm & 0.254 \\
Full active length, cm & 368.9 \\
Partial active length, cm & 243.8 \\
Average linear heat rate, $\mathrm{W} / \mathrm{m}$ & 0.133 \\
\hline
\end{tabular}




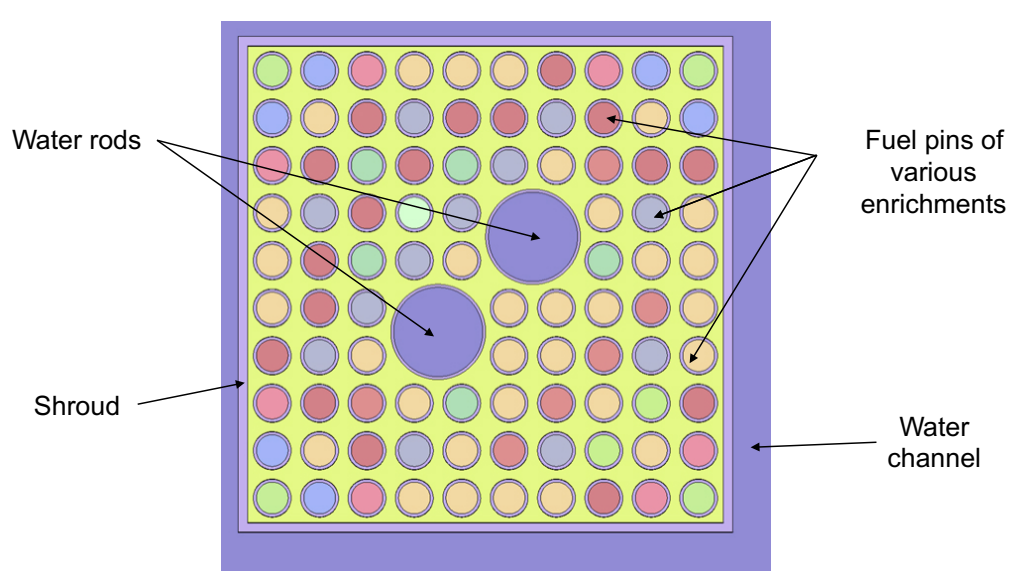

(a)

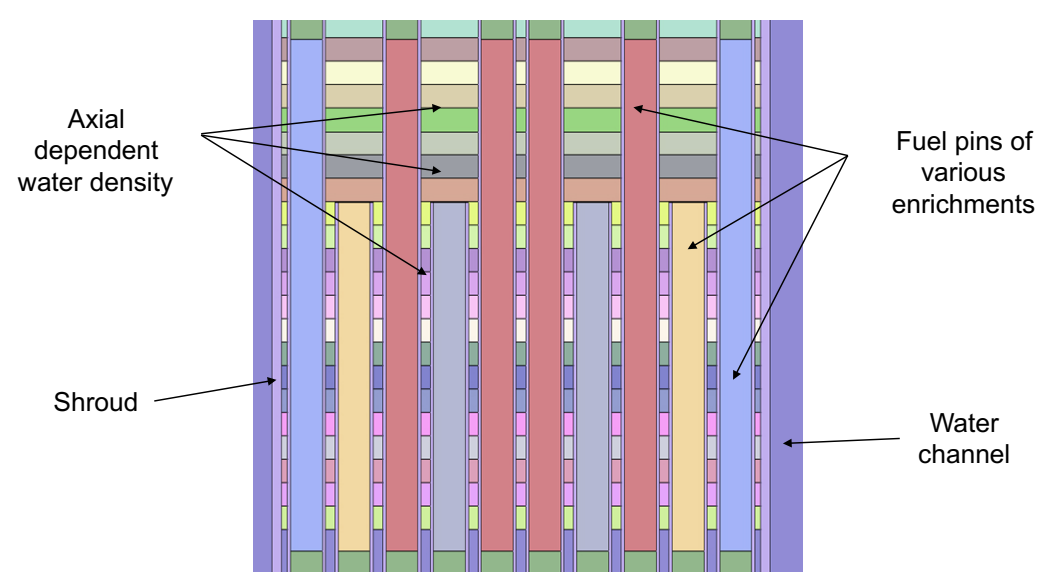

(b)

Figure 2: BWR radial (a) and axial (b) profile as reproduced in Serpent.

The Monte Carlo code Serpent was used for criticality and depletion calculations. Cycle length and attainable burnup were projected from the depletion data of a single assembly. Core average reactivity over a cycle was calculated under the assumption of constant power throughout the assembly lifetime and a radial leakage of 3\% was applied to correct for the infinite lattice model [23]. A three-batch and fourbatch refueling scheme was assumed for the PWR and BWR, respectively. Depletion calculations employed Chebyshev Rational Approximation Method (CRAM) and a high-resolution flux spectrum based on the unified energy-grid structure to calculate one-group cross sections. All material compositions, except fuel composition, were assumed constant during irradiation unless otherwise specified. Reference cycle lengths were found to be 443.2 and 395.6 EFPD (effective full power days) for the reference PWR and BWR models, respectively. 


\section{Results}

\subsection{Ceramic coatings in $P W R$}

Ceramic coatings were applied to the cladding exterior, including instrument and guide tubes, at thicknesses of 10, 50 and $100 \mu \mathrm{m}$; clad outer diameter and thickness were kept constant. Coating materials chosen for this study include three MAX phases $\left(\mathrm{Ti}_{3} \mathrm{AlC}_{2}, \mathrm{Ti}_{2} \mathrm{AlC}\right.$, and $\left.\mathrm{Nb}_{2} \mathrm{AlC}\right)$, and $\mathrm{Ti}_{0.5} \mathrm{Al}_{0.5} \mathrm{~N}$ [24]. A fictitious coating made of Zircaloy-4 was also included in the analysis in order to quantify the affects of reduced moderation due to water displacement by the coating. Properties of candidate coating materials are given in Table 3.

Table 3: Properties of candidate coating materials and Zircaloy-4.

\begin{tabular}{lcc}
\hline Material & Density, g/cm & Thermal conductivity, W/(m K) \\
\hline $\mathrm{Ti}_{3} \mathrm{AlC}_{2}$ & 4.50 & 40.0 \\
$\mathrm{Ti}_{2} \mathrm{AlC}$ & 4.11 & 33.0 \\
$\mathrm{Nb}_{2} \mathrm{AlC}$ & 6.50 & 29.0 \\
$\mathrm{Ti}_{0.5} \mathrm{Al}_{0.5} \mathrm{~N}$ & 3.56 & 5.5 \\
Zircaloy-4 & 6.56 & 20.5 \\
\hline
\end{tabular}

Upon the addition of ceramic coatings, parasitic absorption within the coatings at beginning of life (BOL) increases linearly with thickness (Table 4). As a direct result, absorption and hence fission decreases in the fuel generating a reactivity penalty (Table 4). Such a penalty propagates through the fuel lifetime causing shorter fuel cycles (Table 5). Figure 3 shows the enrichment increase necessary to alleviate the reactivity penalty and match the reference cycle length. Coatings 10-30 $\mu \mathrm{m}$ thick are to be preferred to limit reactivity and cycle length loss, but thicker coatings remain acceptable as enrichment increases are minimal.

Table 4: Neutron absorption by the coating and reactivity change in PWR at beginning of life as a function of coating composition and thickness.

\begin{tabular}{l|ccc|ccc}
\hline \multirow{2}{*}{$\begin{array}{l}\text { Coating } \\
\text { material }\end{array}$} & \multicolumn{3}{|c|}{ Neutron absorption, $\%$} & \multicolumn{3}{c}{ Reactivity change, pcm } \\
\cline { 2 - 7 } & $10 \mu \mathrm{m}$ & $50 \mu \mathrm{m}$ & $100 \mu \mathrm{m}$ & $10 \mu \mathrm{m}$ & $50 \mu \mathrm{m}$ & $100 \mu \mathrm{m}$ \\
\hline $\mathrm{Ti}_{3} \mathrm{AlC}_{2}$ & 0.17 & 0.86 & 1.70 & -198 & -905 & $-1,887$ \\
$\mathrm{Ti}_{2} \mathrm{AlC}$ & 0.15 & 0.76 & 1.51 & -164 & -832 & $-1,671$ \\
$\mathrm{Nb}_{2} \mathrm{AlC}$ & 0.12 & 0.60 & 1.18 & -81 & -628 & $-1,225$ \\
$\mathrm{TiAlN}$ & 0.15 & 0.77 & 1.52 & -130 & -856 & $-1,704$ \\
Zircaloy-4 & 0.02 & 0.09 & 0.18 & -10 & -176 & -428 \\
\hline
\end{tabular}


Table 5: Cycle length penalty (EFPD) in PWR as a function of coating composition and thickness.

\begin{tabular}{lccc}
\hline \multirow{2}{*}{ Coating } & \multicolumn{3}{c}{ Thickness, $\mu \mathrm{m}$} \\
\cline { 2 - 4 } material & 10 & 50 & 100 \\
\hline $\mathrm{Ti}_{3} \mathrm{AlC}_{2}$ & -3.7 & -18.9 & -39.8 \\
$\mathrm{Ti}_{2} \mathrm{AlC}$ & -3.7 & -17.5 & -35.0 \\
$\mathrm{Nb}_{2} \mathrm{AlC}$ & -2.8 & -12.8 & -28.0 \\
$\mathrm{TiAlN}$ & -3.4 & -16.8 & -35.3 \\
Zircaloy-4 & -1.2 & -4.4 & -8.8 \\
\hline
\end{tabular}

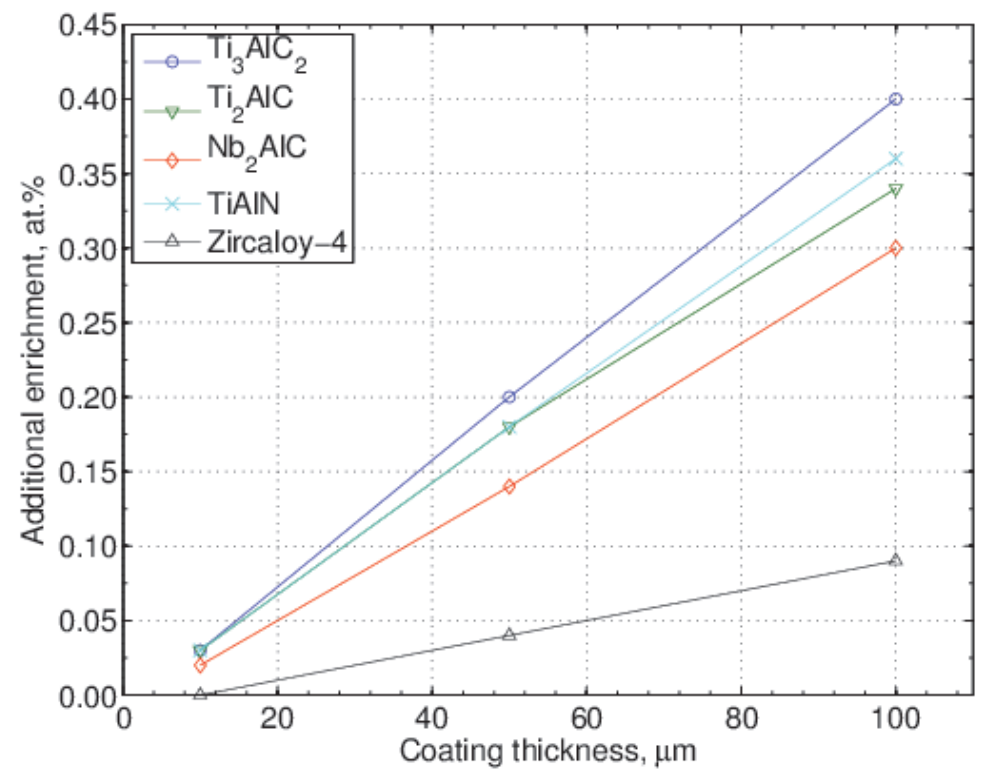

Figure 3: Additional enrichment necessary to match reference cycle length in PWR as a function of coating composition and thickness.

With changes to the fuel assembly geometry and composition its necessary to evaluate the impact on reactivity coefficients. Assuming $50 \mu \mathrm{m}$ thick coatings, the fuel temperature coefficient $\left(\alpha_{\text {fuel }}\right)$ was calculated increasing the fuel temperature only by $100 \mathrm{~K}$; the moderator temperature coefficient $\left(\alpha_{m o d}\right)$ was calculated increasing moderator temperature by $10 \mathrm{~K}$ and modifying its density accordingly; coolant void coefficients were calculated decreasing coolant density by $5 \%$ (small void, $\alpha_{s v}$ ) and $90 \%$ (large void, $\alpha_{l v}$ ). Tables 6 and 7 show the results at beginning and end of life (EOL). All coefficients remain negative and similar to reference values. 
Table 6: Reactivity coefficients in PWR at beginning of life for $50 \mu \mathrm{m}$ coating as a function of composition.

\begin{tabular}{lcccc}
\hline $\begin{array}{l}\text { Coating } \\
\text { material }\end{array}$ & $\alpha_{\text {fuel }}, \mathrm{pcm} / \mathrm{K}$ & $\alpha_{\text {mod }}, \mathrm{pcm} / \mathrm{K}$ & $\alpha_{\text {sv }}, \mathrm{pcm} /$ void $\%$ & $\alpha_{l v}, \mathrm{pcm} /$ void $\%$ \\
\hline $\mathrm{Ti}_{3} \mathrm{AlC}_{2}$ & $-1.14 \pm 0.07$ & $-30.74 \pm 0.66$ & $-101.33 \pm 1.33$ & $-483.45 \pm 0.18$ \\
$\mathrm{Ti}_{2} \mathrm{AlC}$ & $-1.03 \pm 0.07$ & $-30.20 \pm 0.66$ & $-102.04 \pm 1.33$ & $-483.88 \pm 0.18$ \\
$\mathrm{Nb}_{2} \mathrm{AlC}$ & $-1.17 \pm 0.07$ & $-32.82 \pm 0.66$ & $-104.95 \pm 1.32$ & $-507.72 \pm 0.18$ \\
$\mathrm{TiAlN}$ & $-1.17 \pm 0.07$ & $-32.80 \pm 0.66$ & $-103.26 \pm 1.33$ & $-485.27 \pm 0.18$ \\
Zircaloy-4 & $-1.08 \pm 0.06$ & $-29.73 \pm 0.65$ & $-99.45 \pm 1.31$ & $-488.43 \pm 0.17$ \\
\hline Ref. & $-1.12 \pm 0.06$ & $-29.49 \pm 0.65$ & $-96.86 \pm 1.30$ & $-481.80 \pm 0.17$ \\
\hline
\end{tabular}

Table 7: Reactivity coefficients in PWR at end of life for $50 \mu \mathrm{m}$ coating as a function of composition.

\begin{tabular}{lcccc}
\hline $\begin{array}{l}\text { Coating } \\
\text { material }\end{array}$ & $\alpha_{\text {fuel }}, \mathrm{pcm} / \mathrm{K}$ & $\alpha_{\text {mod }}, \mathrm{pcm} / \mathrm{K}$ & $\alpha_{\text {sv }}, \mathrm{pcm} /$ void $\%$ & $\alpha_{l v}, \mathrm{pcm} /$ void $\%$ \\
\hline $\mathrm{Ti}_{3} \mathrm{AlC}_{2}$ & $-2.21 \pm 0.23$ & $-75.80 \pm 2.30$ & $-245.70 \pm 4.61$ & $-976.43 \pm 0.67$ \\
$\mathrm{Ti}_{2} \mathrm{AlC}$ & $-2.94 \pm 0.23$ & $-79.52 \pm 2.29$ & $-250.96 \pm 4.61$ & $-976.33 \pm 0.66$ \\
$\mathrm{Nb}_{2} \mathrm{AlC}$ & $-2.43 \pm 0.23$ & $-78.58 \pm 2.29$ & $-253.96 \pm 4.60$ & $-1019.62 \pm 0.71$ \\
$\mathrm{TiAlN}$ & $-2.29 \pm 0.23$ & $-71.69 \pm 2.29$ & $-244.17 \pm 4.61$ & $-979.49 \pm 0.67$ \\
Zircaloy-4 & $-2.30 \pm 0.23$ & $-73.04 \pm 2.27$ & $-242.04 \pm 4.55$ & $-990.31 \pm 0.67$ \\
\hline Ref. & $-2.54 \pm 0.23$ & $-73.46 \pm 2.18$ & $-241.46 \pm 4.54$ & $-987.11 \pm 0.69$ \\
\hline
\end{tabular}

To ensure all zirconium-alloy surfaces are protected from high temperature steam, it may become necessary to coat spacer grids in addition to fuel rods. A model was set up to assess the effect of coating twelve grids [25] with $50 \mu \mathrm{m}$ thick material. For simplicity grids were not modeled explicitly but uniformly mixed with the coolant. Each grid is $21.9 \mathrm{~cm}$ long, $21.9 \mathrm{~cm}$ wide, $3.81 \mathrm{~cm}$ tall, and grid walls are $0.05 \mathrm{~cm}$ thick $[26,27,28]$. Decreased moderation and excess absorption associated with coated grids enhances the cycle length penalty by about $25 \%$ relative to the case of uncoated grids (Table 8 ). 
Table 8: Comparison of cycle length penalty (EFPD) in PWR with coated and uncoated spacer grids.

\begin{tabular}{lcc}
\hline $\begin{array}{l}\text { Coating } \\
\text { material }\end{array}$ & $\begin{array}{c}\text { Uncoated } \\
\text { grids }\end{array}$ & $\begin{array}{c}\text { Coated } \\
\text { grids }\end{array}$ \\
\hline $\mathrm{Ti}_{3} \mathrm{AlC}_{2}$ & -21.4 & -25.5 \\
$\mathrm{Ti}_{2} \mathrm{AlC}$ & -19.2 & -22.8 \\
$\mathrm{Nb}_{2} \mathrm{AlC}$ & -15.6 & -20.4 \\
$\mathrm{TiAlN}$ & -19.7 & -23.1 \\
Zircaloy-4 & -5.9 & -6.9 \\
\hline
\end{tabular}

\subsection{Ceramic coatings in $B W R$}

In BWRs fuel cladding, water rod cladding, and shroud combine to significantly enhance the surface of zirconium-alloy to be protected compared to the PWR assembly. Ceramic coatings are applied to every surface in direct contact with water, i.e. exterior of the fuel cladding, interior and exterior of the water rods, and interior and exterior of the shroud, and have a pronounced effect on neutron economy. Excess absorption from the shroud, water rods, and their coatings (Table 9) produces substantial cycle length penalties (Table 10) approximately a factor of two larger than those found in the PWR (Table 5). 
Table 9: Neutron absorption in the coatings of BWR core components at beginning of life as a function of coating composition and thickness.

\begin{tabular}{|c|c|c|c|c|}
\hline \multirow{2}{*}{$\begin{array}{l}\text { Coating } \\
\text { thickness, } \mu \mathrm{m}\end{array}$} & \multirow{2}{*}{ Coating material } & \multicolumn{3}{|c|}{ Coating absorption, $\%$} \\
\hline & & Clad & Shroud & Water rod \\
\hline \multirow{5}{*}{10} & $\mathrm{Ti}_{3} \mathrm{AlC}_{2}$ & 0.14 & 0.09 & 0.02 \\
\hline & $\mathrm{Ti}_{2} \mathrm{AlC}$ & 0.12 & 0.08 & 0.01 \\
\hline & $\mathrm{Nb}_{2} \mathrm{AlC}$ & 0.10 & 0.04 & 0.01 \\
\hline & TiAlN & 0.12 & 0.08 & 0.01 \\
\hline & Zircaloy-2 & 0.01 & 0.01 & 0.00 \\
\hline \multirow{5}{*}{50} & $\mathrm{Ti}_{3} \mathrm{AlC}_{2}$ & 0.70 & 0.43 & 0.08 \\
\hline & $\mathrm{Ti}_{2} \mathrm{AlC}$ & 0.62 & 0.38 & 0.07 \\
\hline & $\mathrm{Nb}_{2} \mathrm{AlC}$ & 0.46 & 0.20 & 0.05 \\
\hline & TiAlN & 0.62 & 0.37 & 0.07 \\
\hline & Zircaloy-2 & 0.07 & 0.03 & 0.01 \\
\hline \multirow{5}{*}{100} & $\mathrm{Ti}_{3} \mathrm{AlC}_{2}$ & 1.37 & 0.84 & 0.15 \\
\hline & $\mathrm{Ti}_{2} \mathrm{AlC}$ & 1.22 & 0.75 & 0.13 \\
\hline & $\mathrm{Nb}_{2} \mathrm{AlC}$ & 0.88 & 0.39 & 0.10 \\
\hline & TiAlN & 1.22 & 0.73 & 0.14 \\
\hline & Zircaloy-2 & 0.13 & 0.06 & 0.01 \\
\hline
\end{tabular}

Table 10: Cycle length penalty (EFPD) in BWR as a function of coating composition and thickness.

\begin{tabular}{lccc}
\hline Coating & \multicolumn{3}{c}{ Thickness, $\mu \mathrm{m}$} \\
\cline { 2 - 4 } material & 10 & 50 & 100 \\
\hline $\mathrm{Ti}_{3} \mathrm{AlC}_{2}$ & -6.2 & -29.6 & -63.5 \\
$\mathrm{Ti}_{2} \mathrm{AlC}$ & -5.5 & -27.6 & -55.6 \\
$\mathrm{Nb}_{2} \mathrm{AlC}$ & -2.8 & -14.2 & -31.3 \\
$\mathrm{TiAlN}$ & -5.3 & -27.0 & -54.7 \\
Zircaloy-2 & -0.9 & -3.3 & -5.7 \\
\hline
\end{tabular}

\subsection{Alternative cladding materials in PWR}

In the attempt to cover the variety of proposed alternative cladding solutions, this analysis included four candidate materials: $\mathrm{SiC}, \mathrm{FeCrAl}$, TZM, Alloy 33. Table 11 shows the density and composition of each candidate material. For a fair comparison, besides the alternate materials, all calculations were also performed with Zircaloy-4 cladding in PWR and Zircaloy-2 cladding in BWR. 
Table 11: Density and composition (wt\%) of cladding materials.

\begin{tabular}{lccccccccccccc}
\hline Material & Density, g/cm & $\mathrm{C}$ & $\mathrm{N}$ & $\mathrm{Al}$ & $\mathrm{Si}$ & $\mathrm{Ti}$ & $\mathrm{V}$ & $\mathrm{Cr}$ & $\mathrm{Fe}$ & $\mathrm{Ni}$ & $\mathrm{Cu}$ & $\mathrm{Zr}$ & $\mathrm{Mo}$ \\
\hline $\mathrm{SiC}$ & 3.10 & 30 & - & - & 70 & - & - & - & - & - & - & - & - \\
$\mathrm{FeCrAl}$ & 7.15 & - & - & 5.3 & - & - & - & 22.0 & 72.7 & - & - & - & - \\
$\mathrm{TZM}$ & 10.22 & - & - & - & - & 0.5 & - & - & - & - & - & 0.08 & 99.42 \\
Alloy 33 & 7.90 & 0.01 & 0.4 & - & - & - & - & 33.0 & 33.39 & 31.0 & 0.6 & - & 1.6 \\
\hline
\end{tabular}

To better understand how alternative cladding materials effect neutronic performance, the Zircaloy-4 clad was replaced with $\mathrm{SiC}, \mathrm{FeCrAl}$, TZM , and Alloy 33 clads of same thickness (571.5 $\mu \mathrm{m})$. Among the four materials considered, three show enhanced neutron absorption and large reactivity penalties (Table 12) ${ }^{1}$. $\mathrm{SiC}$ instead features reduced absorption compared with the reference. A parametric analysis was conducted to explore design options that would eliminate cycle length penalties (Table 12). For each candidate material two routes were considered: (1) changing the clad thickness and keeping the fuel enrichment constant; (2) varying the enrichment level with a constant clad thickness.

A variation in clad thickness implies an overall adjustment of fuel pin dimensions. A detailed design procedure for cladding made of the selected materials has not been established; therefore, three approaches were followed upon changing clad thickness: (1) the clad inner diameter (ID) was kept constant; (2) the clad outer diameter (OD) was kept constant whereas pellet and gap size were calculated under the assumption that the volume ratio between gap and fuel would remain as in the reference design, i.e. constant pellet-to-inner clad diameter ratio; (3) the clad OD, as well as the gap thickness were kept constant and the pellet diameter was allowed to change.

Detailed results for each material are presented in the following sections. The main findings are summarized in Table 13. SiC does not generate any significant neutron loss and the clad thickness could be increased

\footnotetext{
${ }^{1}$ In order to track the numerous cases that have been considered we assigned to each case an identification code; a case consists of a unique combination of cladding material, pellet diameter, and gap and clad thickness.
}

Table 12: Neutronics effects of candidate cladding materials in PWR.

\begin{tabular}{lcccc}
\hline Case & $\begin{array}{c}\text { Cladding } \\
\text { material }\end{array}$ & $\begin{array}{c}\text { Cladding } \\
\text { absorption, } \%\end{array}$ & $\begin{array}{c}\text { Reactivity } \\
\text { change, pcm }\end{array}$ & $\begin{array}{c}\text { Cycle length } \\
\text { change, EFPD }\end{array}$ \\
\hline S1 & SiC & 0.36 & +397 & +11.5 \\
F1 & FeCrAl & 6.62 & $-5,831$ & -115.3 \\
T1 & TZM & 12.05 & $-10,532$ & -225.1 \\
A1 & Alloy 33 & 9.43 & $-8,780$ & -174.0 \\
\hline Ref. & Zircaloy-4 & 0.91 & - & - \\
\hline
\end{tabular}


up to $720 \mu \mathrm{m}$ and still match the reference fuel economy. All other alloys present enhanced neutron loss requiring a thinner clad in order to match the cycle length constraint.

Table 13: Clad thickness necessary to meet the cycle length constraint as function of clad material.

\begin{tabular}{lcc}
\hline \multirow{2}{*}{ Material } & \multicolumn{2}{c}{ Thickness, $\mu \mathrm{m}$} \\
\cline { 2 - 3 } & Holding constant ID & Holding constant OD $^{*}$ \\
\hline $\mathrm{SiC}$ & 720 & 620 \\
$\mathrm{FeCrAl}$ & 130 & $270^{* *}$ \\
$\mathrm{TZM}^{* * *}$ & 160 & 280 \\
Alloy 33 & 90 & 210 \\
\hline
\end{tabular}

${ }^{*}$ Results are independent of the approach used to determine

the gap thickness

** Can be increased to $300 \mu \mathrm{m}$ enriching chromium

${ }^{* * *}$ With enriched molybdenum

Neutron absorption in $\mathrm{SiC}$ is smaller than in Zircaloy-4 and a slightly thicker clad could be employed (Table 14). Clad thickness can increase to $620 \mu \mathrm{m}$ and HM load decrease by about $2 \%$ and still achieve acceptable cycle length. If the pellet diameter is kept constant, clad thickness can increase up to $720 \mu \mathrm{m}$. When increasing clad thickness, a reduced moderator-to-fuel volume ratio dominates reactivity loss rather than excess cladding absorption. This is evident when comparing case S2 and S3 with S1. In both cases clad thickness was doubled, but for $\mathrm{S} 3$ half is filled with $\mathrm{SiC}$ and half is void. Reduced moderation generates $76 \%$ of the reactivity drop derived from doubling the clad thickness. Figure 4 shows the change in neutron spectrum as a function of $\mathrm{SiC}$ clad thickness. The most noticeable change is the hardening of the spectrum when clad thickness is doubled as in case $\mathrm{S} 2$.

Table 14: Neutronics effects of SiC cladding in PWR.

\begin{tabular}{lcccccc}
\hline Case & $\begin{array}{c}\text { Compared } \\
\text { to reference }\end{array}$ & $\begin{array}{c}\text { Clad } \\
\text { thickness, } \mu \mathrm{m}\end{array}$ & $\begin{array}{c}\text { HM load, } \\
\mathrm{g} / \mathrm{rod}\end{array}$ & $\begin{array}{c}\text { Clad } \\
\text { absorption, } \%\end{array}$ & $\begin{array}{c}\text { Reactivity } \\
\text { change, pcm }\end{array}$ & $\begin{array}{c}\text { Cycle length } \\
\text { change, EFPD }\end{array}$ \\
\hline $\mathrm{S} 1$ & no change & 571.5 & 2,357 & 0.36 & +397 & +11.5 \\
\hline $\mathrm{S} 2$ & $1,143.0$ & 2,357 & 0.75 & $-2,075$ & -40.5 \\
$\mathrm{~S} 3$ & same ID & $1,143.0^{*}$ & 2,357 & 0.36 & $-1,492$ & -25.2 \\
$\mathrm{~S} 4$ & and gap & 720.0 & 2,357 & 0.48 & -227 & +0.1 \\
\hline $\mathrm{S} 5^{* *}$ & same OD & 620.0 & 2,302 & 0.42 & +505 & -0.1 \\
\hline Ref. & and gap & - & 2,357 & 0.91 & - & - \\
\hline
\end{tabular}

${ }^{*} 571.5 \mu \mathrm{m} \mathrm{SiC}$ and $571.5 \mu \mathrm{m}$ void

${ }^{* *}$ Results are independent of the approach used to determine the gap thickness 


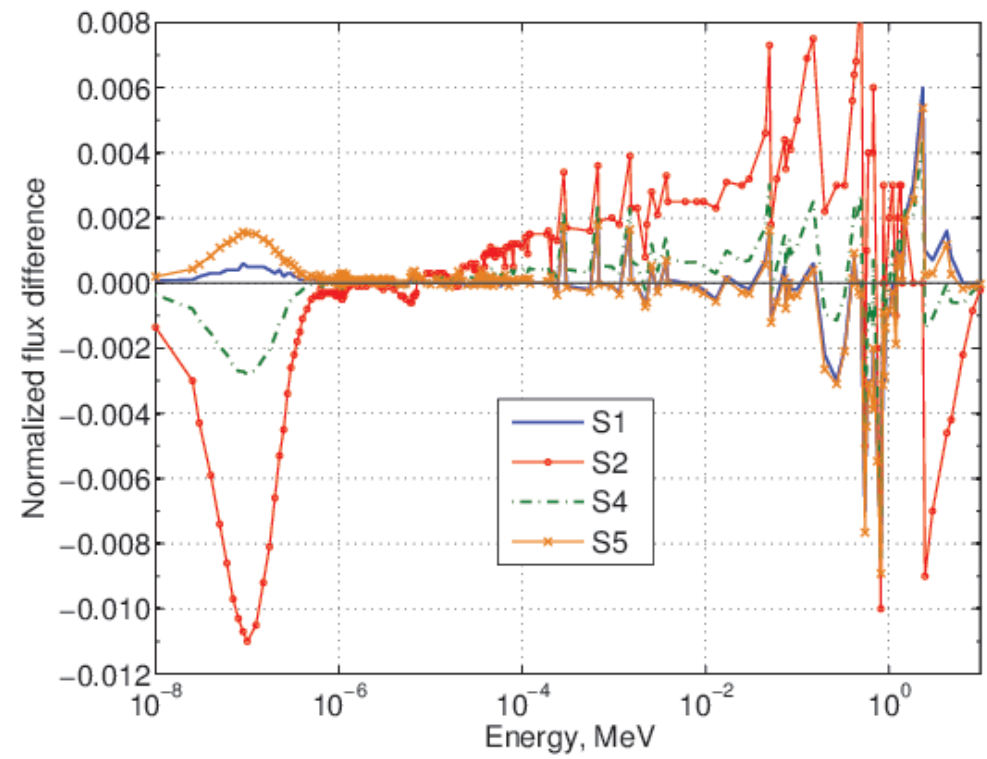

Figure 4: Neutron spectrum deviation from reference at beginning of life for selected $\mathrm{SiC}$ cases.

Replacing Zircaloy-4 with FeCrAl generates a reactivity penalty of 5,831 pcm at BOL and results in a cycle length penalty of 115 EFPD (Table 15). Such penalty is eliminated if the clad thickness can be reduced to $270 \mu \mathrm{m}$ and the HM load increased by about 15\%. If the pellet diameter is kept constant, the clad thickness must be reduced to $130 \mu \mathrm{m}$. Figure 5 shows the change in neutron spectrum as a function of FeCrAl clad thickness. Enhanced thermal absorption results in a slightly harder spectrum for case F1. Smaller diameter pins as in case F5, instead, feature softer spectrum.

Table 15: Neutronics effects of FeCrAl cladding in PWR.

\begin{tabular}{lcccccc}
\hline Case & $\begin{array}{c}\text { Compared } \\
\text { to reference }\end{array}$ & $\begin{array}{c}\text { Clad } \\
\text { thickness, } \mu \mathrm{m}\end{array}$ & $\begin{array}{c}\text { HM load, } \\
\text { g/rod }\end{array}$ & $\begin{array}{c}\text { Clad } \\
\text { absorption, } \%\end{array}$ & $\begin{array}{c}\text { Reactivity } \\
\text { change, pcm }\end{array}$ & $\begin{array}{c}\text { Cycle length } \\
\text { change, EFPD }\end{array}$ \\
\hline F1 & no change & 571.5 & 2,357 & 6.62 & $-5,831$ & -115.3 \\
\hline F2 & & 400.0 & 2,357 & 4.89 & $-3,510$ & -71.7 \\
F3 & same ID & 300.0 & 2,357 & 3.71 & $-2,002$ & -44.8 \\
F4 & and gap & 200.0 & 2,357 & 2.49 & -639 & -17.4 \\
F5 & & 130.0 & 2,357 & 1.63 & -158 & -0.2 \\
\hline F6 & \multirow{2}{*}{ same OD } & 400.0 & 2,555 & 4.61 & $-4,350$ & -54.6 \\
F7 & and gap & 300.0 & 2,673 & 3.38 & $-3,458$ & -12.3 \\
F8 & & 270.0 & 2,709 & 3.02 & $-3,211$ & +0.8 \\
\hline Ref. & - & 571.5 & 2,357 & 0.91 & - & - \\
\hline
\end{tabular}

${ }^{*}$ Results are independent of the approach used to determine the gap thickness 


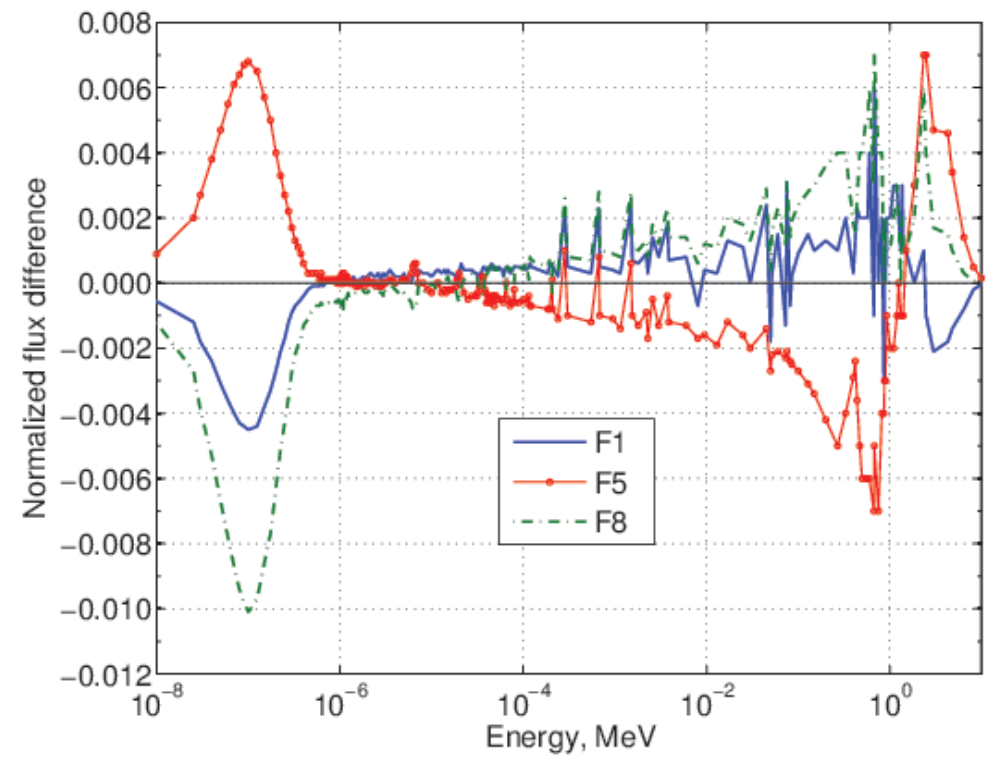

Figure 5: Neutron spectrum deviation from reference at beginning of life for selected $\mathrm{FeCrAl}$ cases.

Table 16 breaks down neutron absorption by FeCrAl components: ${ }^{56} \mathrm{Fe}$ (91.75\% natural abundance) is the major absorber; ${ }^{53} \mathrm{Cr}$ (9.50\% natural abundance) is the second larger absorption. In the attempt to reduce absorption in $\mathrm{FeCrAl}$ the effectiveness of eliminating (reducing to $0.1 \%$ of $\mathrm{Cr}$ ) ${ }^{53} \mathrm{Cr}$ was tested. This resulted in a $300 \mu \mathrm{m}$ thick clad meeting the cycle length requirement as opposed to a $270 \mu \mathrm{m}$ thick clad. It remains to be evaluated if such improvement is enough to justify the cost of chromium ${ }^{53} \mathrm{Cr}$ depletion.

Table 16: Relative neutron absorption in FeCrAl by constituent isotopes.

\begin{tabular}{ccc}
\hline Element & $\begin{array}{c}\text { Natural } \\
\text { abundance, at.\% }\end{array}$ & $\begin{array}{c}\text { Relative } \\
\text { absorption, \% }\end{array}$ \\
\hline${ }^{27} \mathrm{Al}$ & 100.00 & 1.01 \\
${ }^{50} \mathrm{Cr}$ & 4.35 & 6.13 \\
${ }^{52} \mathrm{Cr}$ & 83.79 & 5.92 \\
${ }^{53} \mathrm{Cr}$ & 9.50 & 15.17 \\
${ }^{54} \mathrm{Cr}$ & 2.37 & 0.08 \\
${ }^{54} \mathrm{Fe}$ & 5.80 & 3.70 \\
${ }^{56} \mathrm{Fe}$ & 91.72 & 66.11 \\
${ }^{57} \mathrm{Fe}$ & 2.20 & 1.55 \\
${ }^{58} \mathrm{Fe}$ & 0.28 & 0.12 \\
\hline
\end{tabular}

TZM is a strong neutron absorber. More than $12 \%$ of neutrons are absorbed in the clad if Zircaloy-4 is replaced with TZM (case T1 in Table 17) resulting in a 225 EFPD cycle length penalty; therefore, it was 
assumed that TZM can not be considered a viable LWR cladding material unless molybdenum is depleted of ${ }^{95}$ Mo. In such case absorption in TZM clad decreases by a factor of 2.3 (case T2 in Table 17). During this analysis it was assumed that ${ }^{95}$ Mo would be isotopically separated from the other molybdenum isotopes and its concentration reduced to $0.1 \%$. Under these assumptions a TZM clad still generates a reactivity penalty of 3,689 pcm at BOL and a cycle length penalty of 87 EFPD. Such penalty is eliminated if the clad thickness can be reduced to $280 \mu \mathrm{m}$ and the HM load increased by about $14 \%$. If the pellet diameter is kept constant, the clad thickness must be reduced to $160 \mu \mathrm{m}$. Figure 6 shows the change in neutron spectrum as a function of TZM clad thickness. Trends are similar to those observed for FeCrAl.

Table 17: Neutronics effects of TZM cladding in PWR.

\begin{tabular}{lcccccc}
\hline Case & $\begin{array}{c}\text { Compared } \\
\text { to reference }\end{array}$ & $\begin{array}{c}\text { Clad } \\
\text { thickness, } \mu \mathrm{m}\end{array}$ & $\begin{array}{c}\text { HM load, } \\
\mathrm{g} / \mathrm{rod}\end{array}$ & $\begin{array}{c}\text { Clad } \\
\text { absorption, } \%\end{array}$ & $\begin{array}{c}\text { Reactivity } \\
\text { change, pcm }\end{array}$ & $\begin{array}{c}\text { Cycle length } \\
\text { change, EFPD }\end{array}$ \\
\hline T1 & $\begin{array}{c}\text { no change, } \\
\text { natural Mo }\end{array}$ & 571.5 & 2,357 & 12.05 & $-10,532$ & -225.1 \\
\hline T2 & no change & 571.5 & 2,357 & 5.23 & $-3,689$ & -87.1 \\
\hline T3 & & 400.0 & 2,357 & 3.82 & $-1,955$ & -49.8 \\
T4 & same ID & 300.0 & 2,357 & 2.91 & -958 & -28.5 \\
T5 & and gap & 200.0 & 2,357 & 2.00 & 58 & -8.4 \\
T6 & & 160.0 & 2,555 & 1.63 & 391 & -0.1 \\
\hline T7 & same OD & 400.0 & 2,673 & 3.94 & $-3,121$ & -39.8 \\
T8 & and gap ${ }^{*}$ & 300.0 & 2,697 & 3.06 & $-2,705$ & -6.5 \\
T9 & & 280.0 & 2,559 & 2.88 & $-2,630$ & +0.3 \\
\hline Ref. & - & 571.5 & & 0.91 & - & - \\
\hline
\end{tabular}

${ }^{*}$ Results are independent of the approach used to determine the gap thickness 


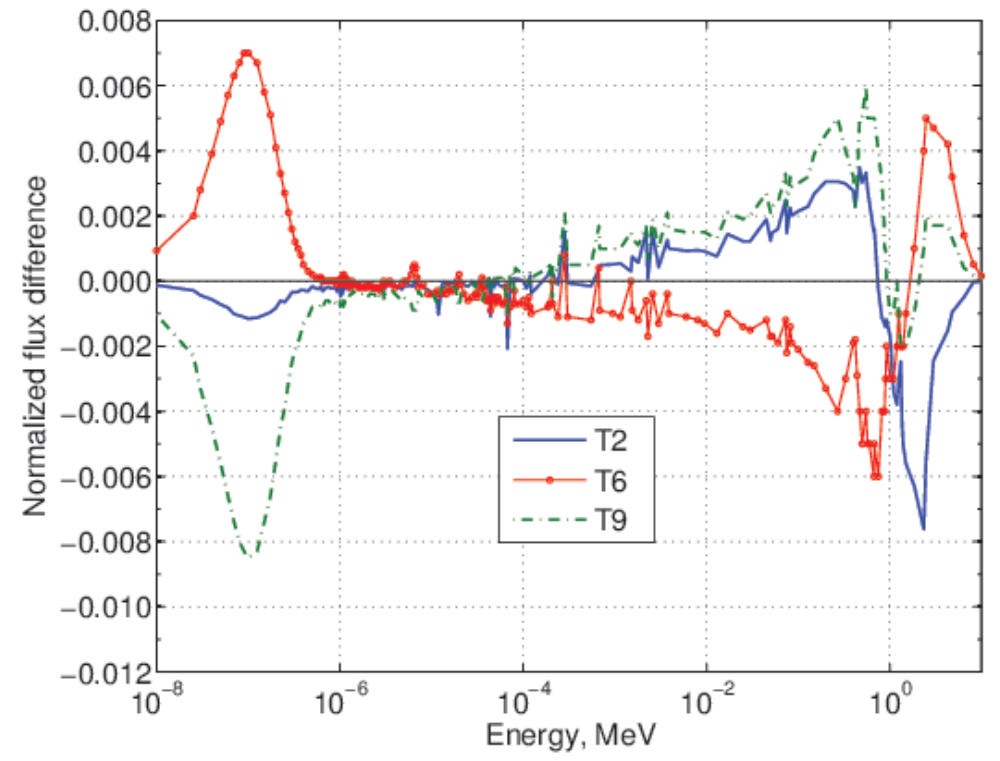

Figure 6: Neutron spectrum deviation from reference at beginning of life for selected TZM cases.

Replacing Zircaloy-4 with Alloy 33 generates a reactivity penalty of $8,780 \mathrm{pcm}$ at BOL and results in a cycle length penalty of 174 EFPD (Table 18). Such penalty is eliminated if the clad thickness can be reduced to $210 \mu \mathrm{m}$ and the HM load increased by about 18\%. If the pellet diameter is kept constant, the clad thickness must be reduced to $90 \mu \mathrm{m}$. Isotopic enrichment was not considered for Alloy 33 because it contains multiple high absorbing nuclides. Figure 7 shows the change in neutron spectrum as a function of Alloy 33 clad thickness. Trends are similar to those observed for FeCrAl.

Table 18: Neutronics effects of Alloy 33 cladding in PWR.

\begin{tabular}{lcccccc}
\hline Case & $\begin{array}{c}\text { Compared } \\
\text { to reference }\end{array}$ & $\begin{array}{c}\text { Clad } \\
\text { thickness, } \mu \mathrm{m}\end{array}$ & $\begin{array}{c}\text { HM load, } \\
\mathrm{g} / \mathrm{rod}\end{array}$ & $\begin{array}{c}\text { Clad } \\
\text { absorption, } \%\end{array}$ & $\begin{array}{c}\text { Reactivity } \\
\text { change, pcm }\end{array}$ & $\begin{array}{c}\text { Cycle length } \\
\text { change, EFPD }\end{array}$ \\
\hline A1 & no change & 571.5 & 2,357 & 7.02 & $-8,780$ & -174.0 \\
\hline A2 & & 2,357 & 7.02 & $-5,587$ & -114.5 \\
A3 & same ID & 300.0 & 2,357 & 5.34 & $-3,638$ & -76.0 \\
A4 & and gap & 200.0 & 2,357 & 3.62 & $-1,693$ & -39.2 \\
A5 & & 2,357 & 1.65 & +368 & +0.8 \\
\hline A6 & same OD & 400.0 & 2,555 & 6.64 & $-6,435$ & -99.9 \\
A7 & and gap & 300.0 & 2,673 & 4.91 & $-5,009$ & -48.6 \\
A8 & 210.0 & 2,782 & 3.40 & $-3,757$ & -0.4 \\
\hline Ref. & - & 571.5 & 2,357 & 0.91 & - & - \\
\hline
\end{tabular}

${ }^{*}$ Results are independent of the approach used to determine the gap thickness 


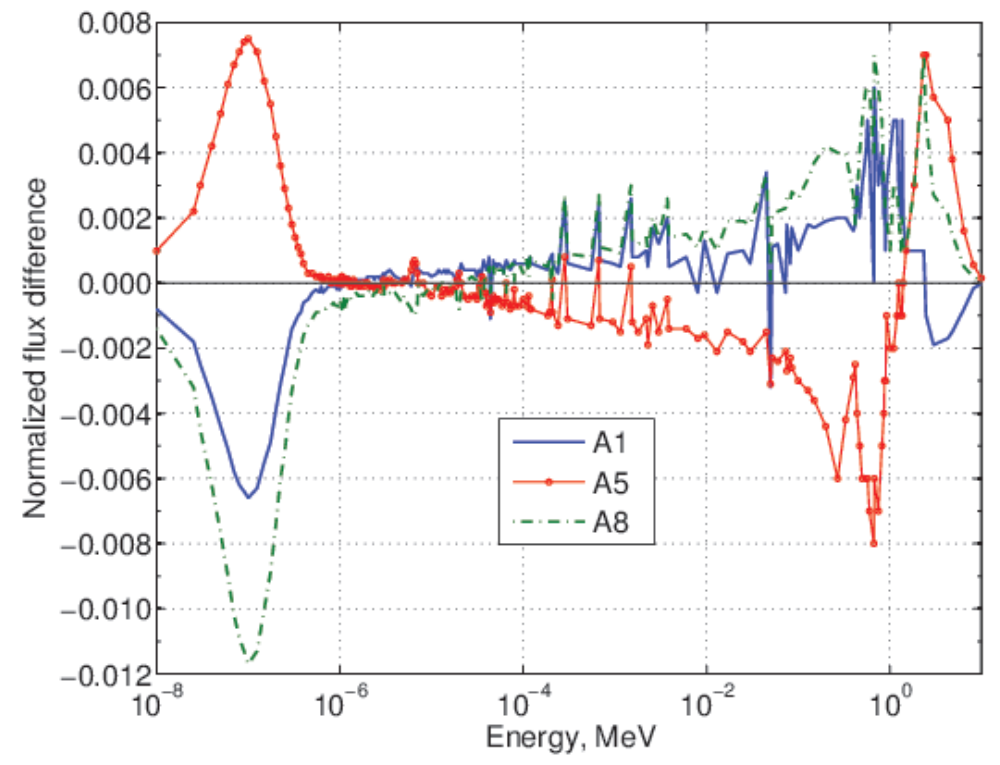

Figure 7: Neutron spectrum deviation from reference at beginning of life for selected Alloy 33 cases.

A second parametric analysis was conducted searching for the fuel enrichment necessary to match the reference cycle length as a function of clad thickness. It was found that $\mathrm{FeCrAl}$ requires incrementing enrichment by $0.30 \%$ for every additional $100 \mu \mathrm{m}$ starting from the minimum thickness established above; TZM $(0.1 \%$ ${ }^{95} \mathrm{Mo}$ ) requires about $0.25 \%$ per $100 \mu \mathrm{m}$, and Alloy 33 requires about $0.45 \%$ per $100 \mu \mathrm{m}$ (Figures 8 and 9). Due to increased reactivity and thicker clad it is unnecessary to enrich fuel with SiC cladding.

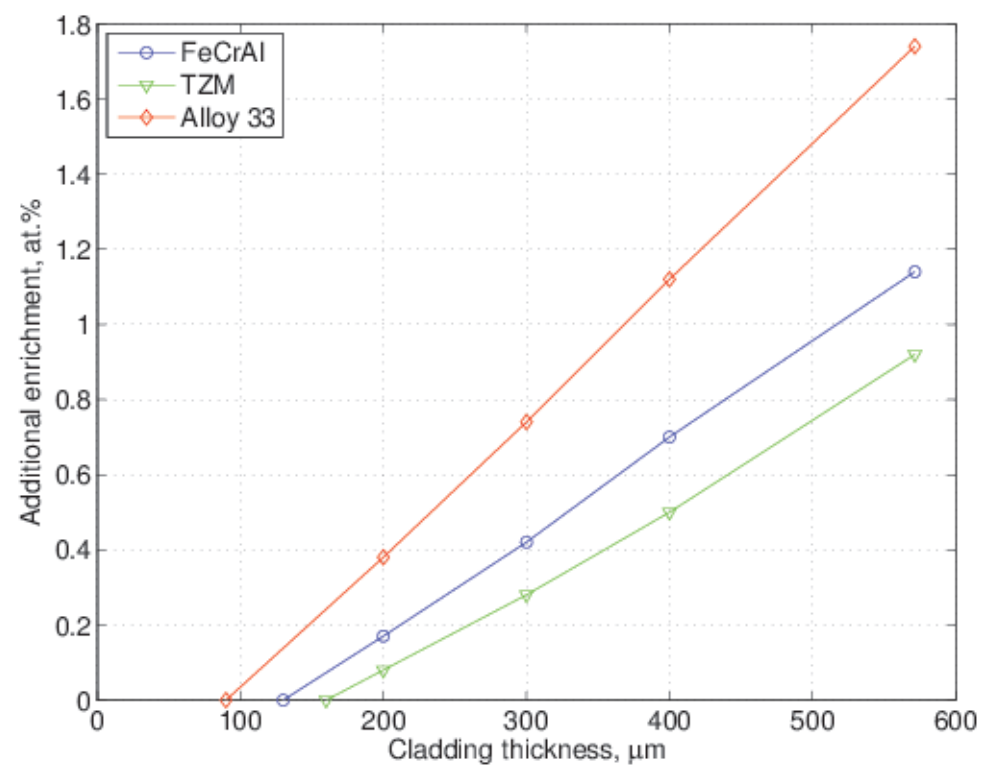

Figure 8: Additional enrichment necessary to match reference cycle length in PWR as a function of cladding thickness when the ID is held constant. 


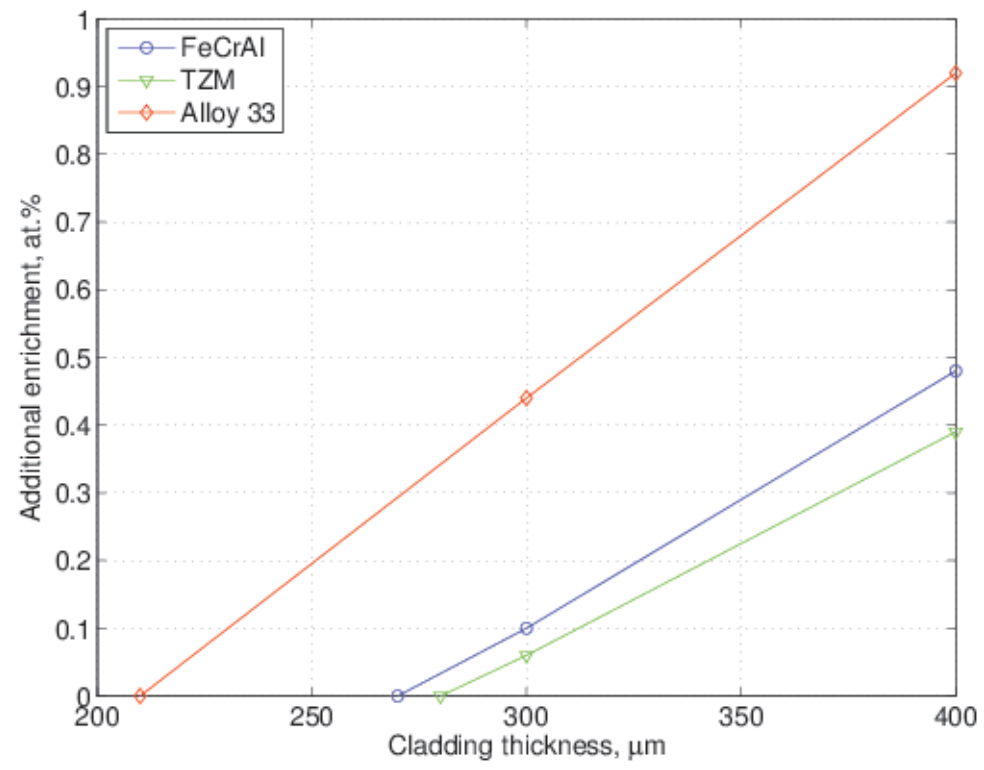

Figure 9: Additional enrichment necessary to match reference cycle length in PWR as a function of cladding thickness when the OD is held constant.

Reactivity coefficients were also calculated to ensure comparable performance for candidate cladding materials at the reference thickness $(571.5 \mu \mathrm{m})$. Fuel temperature coefficients are similar to the reference (Table 19). Moderator temperature coefficients, and small and large void coefficients experience larger deviations from the reference with TZM being the most significant (Tables 19 - 20). Molybdenum, specifically ${ }^{92} \mathrm{Mo},{ }^{94} \mathrm{Mo}$, and ${ }^{100} \mathrm{Mo}$, is a strong resonance absorber. Hardening of the spectrum by voiding leads to enhanced capture in the resonances and larger reactivity drop.

Table 19: Reactivity coefficients in PWR at beginning of life as a function of cladding material.

\begin{tabular}{lccccc}
\hline \multirow{2}{*}{ Case } & $\begin{array}{c}\text { Cladding } \\
\text { material }\end{array}$ & $\alpha_{\text {fuel }}, \mathrm{pcm} / \mathrm{K}$ & $\alpha_{\text {mod }}, \mathrm{pcm} / \mathrm{K}$ & $\alpha_{s v}, \mathrm{pcm} /$ void $\%$ & $\alpha_{l v}, \mathrm{pcm} /$ void $\%$ \\
\hline $\mathrm{S} 1$ & $\mathrm{SiC}$ & $-1.10 \pm 0.06$ & $-29.15 \pm 0.64$ & $-95.04 \pm 1.28$ & $-455.87 \pm 0.17$ \\
$\mathrm{~F} 1$ & $\mathrm{FeCrAl}$ & $-1.24 \pm 0.08$ & $-32.00 \pm 0.76$ & $-99.98 \pm 1.51$ & $-469.29 \pm 0.18$ \\
$\mathrm{~T} 2$ & $\mathrm{TZM}$ & $-1.22 \pm 0.07$ & $-41.86 \pm 0.76$ & $-132.13 \pm 1.52$ & $-643.75 \pm 0.25$ \\
$\mathrm{~A} 1$ & Alloy 33 & $-1.55 \pm 0.09$ & $-32.58 \pm 0.91$ & $-105.64 \pm 1.82$ & $-482.26 \pm 0.20$ \\
\hline Ref. & Zircaloy-4 & $-1.12 \pm 0.06$ & $-29.49 \pm 0.65$ & $-96.86 \pm 1.30$ & $-481.82 \pm 0.17$ \\
\hline
\end{tabular}


Table 20: Reactivity coefficients in PWR at end of life as a function of cladding material.

\begin{tabular}{lccccc}
\hline Case & $\begin{array}{c}\text { Cladding } \\
\text { material }\end{array}$ & $\alpha_{\text {fuel }}, \mathrm{pcm} / \mathrm{K}$ & $\alpha_{\text {mod }}, \mathrm{pcm} / \mathrm{K}$ & $\alpha_{s v}, \mathrm{pcm} /$ void $\%$ & $\alpha_{l v}, \mathrm{pcm} /$ void \% \\
\hline $\mathrm{S} 1$ & $\mathrm{SiC}$ & $-2.29 \pm 0.22$ & $-72.38 \pm 2.23$ & $-238.51 \pm 4.49$ & $-950.62 \pm 0.64$ \\
$\mathrm{~F} 1$ & $\mathrm{FeCrAl}$ & $-2.79 \pm 0.25$ & $-77.56 \pm 2.51$ & $-252.67 \pm 5.05$ & $-932.65 \pm 0.68$ \\
$\mathrm{~T} 2$ & $\mathrm{TZM}$ & $-2.46 \pm 0.26$ & $-93.90 \pm 2.48$ & $-295.28 \pm 5.18$ & $-1272.97 \pm 0.94$ \\
$\mathrm{~A} 1$ & Alloy 33 & $-2.57 \pm 0.26$ & $-79.64 \pm 2.64$ & $-258.72 \pm 5.51$ & $-928.35 \pm 0.68$ \\
\hline Ref. & Zircaloy-4 & $-2.48 \pm 0.23$ & $-73.96 \pm 2.18$ & $-241.09 \pm 4.54$ & $-987.07 \pm 0.69$ \\
\hline
\end{tabular}

\subsection{Alternative cladding materials in $B W R$}

The inclusion of large water rods and shroud drastically reduces reactivity and shortens cycle lengths for BWRs (Table 21) with the exception of $\mathrm{SiC}$ that experiences $18 \mathrm{EFPD}$ longer fuel cycle. A BWR with TZM-made $\left(0.1 \%{ }^{95} \mathrm{Mo}\right)$ core components encounters a $50 \%$ reduction in cycle length. The cycle length for $\mathrm{FeCrAl}$ and Alloy 33 could not be calculated since criticality was never reached. Although these data are provided for completeness, extremely large penalties are unreasonable for power reactors and will require multiple alterations to fuel rod geometry and average assembly enrichment, but such tasks were beyond the scope of this work.

Table 21: Neutronics effects of candidate cladding materials in BWR.

\begin{tabular}{lccccccc}
\hline \multirow{2}{*}{$\begin{array}{l}\text { Cladding } \\
\text { material }\end{array}$} & \multicolumn{5}{c}{ Neutron absorption, $\%$} & Reactivity & \multirow{2}{*}{$\begin{array}{c}\text { Cycle length } \\
\text { change, EFPD }\end{array}$} \\
\cline { 2 - 5 } & Fuel & Clad & Water Rod & Shroud & Coolant & change, pcm & chan \\
\hline SiC & 92.92 & 0.39 & 0.02 & 0.41 & 5.86 & $+1,055$ & +18.3 \\
FeCrAl & 81.03 & 6.30 & 0.42 & 7.10 & 4.94 & $-16,388$ & - \\
TZM $^{*}$ & 85.37 & 4.82 & 0.32 & 3.59 & 5.49 & $-7,757$ & -196.7 \\
Alloy 33 & 76.43 & 8.66 & 0.60 & 9.50 & 4.64 & $-24,318$ & - \\
\hline Ref. & 92.06 & 0.90 & 0.06 & 0.75 & 5.80 & - & - \\
\hline
\end{tabular}

${ }^{*}$ With $0.1 \%{ }^{95} \mathrm{Mo}$

\section{Conclusions}

Multiple design approaches for accident tolerant fuels are available, ranging from minimal cladding additions to complete fuel redesign. This study reviewed the neutronic impact of protecting conventional LWR cladding with thin ceramic coatings or replacing zirconium-alloy with alternative materials. It was found that when adding thin $(\leq 100 \mu \mathrm{m})$ ceramic coatings, the corresponding reactivity penalties are small and proportional to the coating thickness, and can be alleviated if fuel enrichment is increased by $0.5 \%$ or less. Introducing coated spacer grids increases cycle length penalty by an additional $25 \%$. Coatings $50 \mu \mathrm{m}$ thick 
show no major impact on reactivity coefficients as all values remain negative and similar to reference. Due to larger quantities of zirconium alloy and ceramic coatings, BWR reactivity and cycle length losses are a factor of two greater than in PWR. For materials considered in this study it is necessary to minimize the coating thickness $(10-30 \mu \mathrm{m})$ to limit neutronic penalties.

Substituting FeCrAl, TZM, and Alloy 33 for zirconium-alloy cladding generates fuel cycles 115 to 225 EFPD shorter, whereas $\mathrm{SiC}$ improves neutron economy. A parametric analysis showed that FeCrAl, TZM, and Alloy 33 can match the reference cycle length when the cladding ID remains constant if the clad thickness is reduced to $130 \mu \mathrm{m}, 160 \mu \mathrm{m}$, and $90 \mu \mathrm{m}$ respectively. Meanwhile the clad thickness can be increased to $720 \mu \mathrm{m}$ for SiC. When cladding OD remains at reference value, cladding thickness for FeCrAl, TZM, and Alloy 33 must be reduced to $270 \mu \mathrm{m}, 280 \mu \mathrm{m}$, and $210 \mu \mathrm{m}$ respectively and the HM load increased by 14-18\%. SiC thickness, instead, can be increased to $620 \mu \mathrm{m}$ and the HM load decreased by about $2 \%$. A second parametric analysis determined that an increase of enrichment equal to $0.30 \%$ for $\mathrm{FeCrAl}, 0.25 \%$ for TZM, and $0.45 \%$ for Alloy 33 is necessary for every $100 \mu \mathrm{m}$ of additional cladding thickness starting from the minimum values listed above. Although such increase can be considered small, it might lead to exceed the current commercial enrichment limit of $5 \%$. When replacing BWR cladding, SiC lengthens the fuel cycle

by 18 EFPD and TZM with $0.1 \%{ }^{95}$ Mo reduces it by a factor of two. Conversely, severe neutronic penalties stemming from $\mathrm{FeCrAl}$ and Alloy 33 prevented criticality.

This study assessed the requirements for ceramic coatings and cladding materials necessary to meet the neutronics performance of current claddings. The feasibility of manufacturing coatings or thin cladding and their mechanical performance remain to be established in future work. Furthermore, the improvements on current cladding in beyond design basis accident need to be carefully addressed.

\section{Acknowledgements}

This research is being performed using funding received from the DOE Office of Nuclear Energy's Nuclear Energy University Programs.

\section{References}

[1] K.A. Terrani, S. J. Zinkle, L.L. Snead, Advanced Oxidation-Resistant Iron-Based Alloys for LWR Fuel Cladding, Journal of Nuclear Materials 448 (1-3) (2013) 420-435.

[2] F.J. Erbacher, S. Leistikow, A Review of Zircaloy Fuel Cladding Behavior in a Loss-of-Coolant Accident, Tech. Rep. KfK 3973, Institut fur Reaktorbauelemente (1985).

[3] S.J. Zinkle, K.A. Terrani, J.C. Gehin, L.J. Ott, L.L. Snead, Accident tolerant fuels for LWRs: A perspective, Journal of Nuclear Materials 448 (1-3) (2014) 374-379.

[4] M. W. Barsoum, M. Radovic, Elastic and Mechanical Properties of the MAX Phases, Annual Review of Materials Research 41 (2011) 195-227. 
[5] S. M. Bragg-Sitton, Light Water Reactor Sustainability Program - Advanced LWR Nuclear Fuel Cladding System Development Technical Program Plan, Tech. Rep. INL/MIS-12-25696, Idaho National Laboratory (2012).

[6] Y. Liu, I. Bhamji, P. Withers, D. Wolfe, A. Motta, M. Preuss, Evaluation of the interfacial shear strength and residual stress of TiAlN coating on ZIRLO fuel cladding using a modified shear-lag model approach, Journal of Nuclear Materials 466 (2015) 718-727.

[7] J. X. Deng, F. F. Wu, Y. S. Lian, Y. Q. Yiang, S. P. Li, International Journal of Refractory Metals and Hard Materials 35 .

[8] F. Khatkhatay, L.Jiao, J. Jian, W. Zhang, Z. Jiao, J. Gan, H. Zhang, X. Zhang, H. Wang, Superior corrosion resistance properties of TiN-based coatings on Zircaloy tubes in supercritical water, Journal Nuclear Materials 451 (2014) 346-351.

[9] G. Griffith, U.S. Department of Energy Accident-Resistant SiC Clad Nuclear Fuel Development, Tech. Rep. INL/CON-11-23186, Idaho National Laboratory (2011).

[10] N. M. George, K. A. Terrani, J. Powers, A. Worrall, I. Maldonado, Neutronic analysis of candidate accident-tolerant cladding concepts in pressurized water reactors, Annals of Nuclear Energy 75 (2015) 703-712.

[11] K. Yueh, K. A, Terrani, Silicon carbide composite for light water reactor fuel assembly applications, Journal of Nuclear Materials 448 (1-3) (2014) 380-388.

[12] Y. Katoh, K. Ozawa, C. Shih, T. Nozawa, R. J. Shinavski, A. Hasegawa, L. L. Snead, Continuous SiC fiber, CVI SiC matrix composites for nuclear applications: Properties and irradiation effects, Journal of Nuclear Materials 448 (1-3) (2014) 448-476.

[13] K. Terrani, Y. Yang, Y.-J. Kim, R. Rebak, H. M. III, T. Gerczak, Hydrothermal corrosion of SiC in LWR coolant environments in the absence of irradiation, Journal of Nuclear Materials 465 (2015) 488-498.

[14] B. A. Pint, K. A. Terrani, A. Nelson, S. Parker, A. Parkison, High Temperature Steam Oxidation Testing of Candidate Accident Tolerant Fuel Cladding Materials, Tech. Rep. ORNL/TM-2013/540, Oak Ridge National Laboratory (2013).

[15] L. Goldstein, O. Reyes, A. A. Strasser, Evaluation of Fuel-Cladding Properties at High Temperatures, Tech. Rep. NP-5427, Electric Power Research Institute (1988).

[16] G. Youinou, R. Sonat Sen, Enhanced Accident Tolerant Fuels for LWRs - A Preliminary Systems Analysis, Tech. Rep. INL/EXT-13-30211, Idaho National Laboratory (2013).

[17] J. Leppanen, PSG2/Serpent - A Continuous-energy Monte Carlo Reactor Physics Burnup Calculation Code, Tech. rep., VTT Technical Research Centre of Finland (2012). 
[18] Westinghouse AP1000 Design Control Document Rev. 19 - Chapter 4. Reactor, Westinghouse Electric Company LLC, 2011.

[19] E. Greenspan, M. Fratoni, F. Ganda, F. Ginex, D. Olander, N. Todreas, P. Diller, P. Ferroni, J. Malen, A. Romano, C. Shuffler, J. Trant, B. Petrovic, H. Garkisch, Hydride Fuel for LWRs - Project Overview, Nuclear Engineering and Design 239 (2009) 1374-1405.

[20] M. Fensin, Optimum Boiling Water Reactor Fuel Design Strategies to Enhance Reactor Shutdown by the Standby Liquid Control System, Master's thesis, University of Florida (2004).

[21] ABWR: General Plant Description - Chapter 6, General Electric, 2006.

[22] G. I. Maldonado, J. Galloway, H. Hernandez, Recycling heterogeneous americium targets in a boiling water reactor, Annals of Nuclear Energy 37 (2010) 256-264.

[23] M. Fratoni, E. Greenspan, Neutronic design of hydride fueled BWRs, Nuclear Engineering and Design 239 (2009) 1531-1543.

[24] C. Chokwatvikul, S. Larpkiattaworn, S. Surinphong, C. Bosebok, P. Termsuksawad, Effect of Nitrogen Partial Pressure an Characteristic and Mechanical Properties of Hard Coating TiAlN Film, Journal of Metals, Materials and Minerals 21 (1) (2011) 115-119.

[25] Westinghouse AP1000 Design Control Document Rev. 19 - Chapter 4.2 Fuel System Design, Westinghouse Electric Company LLC, 2011.

[26] E. E. Dominguez-Ontiveros, Y. A. Hassan, M. E. Conner, Z. Karoutas, Experimental Benchmark Data for PWR Rod Bundle with Spacer Grids, Nuclear Engineering and Design 253 (2012) 396-405.

[27] J. Yan, B. Kochunas, M. Hursin, T. Downar, Z. Karoutas, E. Baglietto, Coupled Computational Fluid Dynamics and MOC Neutronic Simulations of Westinghouse PWR Fuel Assemblies with Spacer Grids, Tech. Rep. NURETH14-254, University of Michigan, Ann Arbor (2011).

[28] A Rubin, A. Schoedel, M. Avramova, OECD/NRC Benchmark Based on NUPEC PWR Subchannel and Bundle Tests (PSBT), Tech. Rep. NEA/NSC/DOC(2010)1, The Pennsylvania State University (2010). 